\title{
Population pharmacokinetics of exogenous biotin and the relationship between biotin serum levels and in vitro immunoassay interference
}

\author{
Paul Grimsey ${ }^{\ddagger 1}$, Nicolas Frey $y^{\ddagger}, 2$, Garnet Bendig ${ }^{3}$, Juergen Zitzler ${ }^{3}$, Oliver Lorenz ${ }^{3}$, Dusanka \\ Kasapic ${ }^{4}$ \& Christian E Zaugg ${ }^{*}, 4$ \\ ${ }^{1}$ Roche Pharmaceuticals, Roche Innovation Center Welwyn, Welywn Garden City, UK \\ ${ }^{2}$ Roche Pharmaceuticals, Basel, Switzerland \\ ${ }^{3}$ Roche Diagnostics GmbH, Penzberg, Germany \\ ${ }^{4}$ Roche Diagnostics International Ltd, Forrenstrasse 2, CH-6343 Rotkreuz, Switzerland \\ * Author for correspondence: Tel.: +41 79857 00; Christian.Zaugg.cz1@roche.com \\ $¥$ Authors contributed equally
}

\begin{abstract}
Aim: Biotin in human serum is a potential interfering factor for streptavidin-biotin-based assays. We aimed to evaluate the effective half-life of biotin and biotin metabolites, and establish a pharmacokinetic (PK) model to simulate the time taken for the biotin concentration to fall below a series of thresholds. Materials \& methods: PK properties of biotin (5, 10 and $20 \mathrm{mg}$ daily) were evaluated in healthy participants. Biotin serum concentrations were simulated for high-dose regimens ( $1 \mathrm{mg}$ daily to $300 \mathrm{mg}$ q.i.d.) using a population PK model. Results: Washout periods required for biotin concentrations to reach thresholds ranging from 10 to $100 \mathrm{ng} / \mathrm{ml}$ were successfully simulated. Conclusion: Our simulations provide valuable guidance on biotin washout periods necessary to avoid false assay results.
\end{abstract}

First draft submitted: 11 July 2017; Accepted for publication: 31 August 2017; Published online: 14 September 2017

Keywords: accumulation $\bullet$ biotin $\bullet$ computer model $\bullet$ diagnostic tests $\bullet$ exposure $\bullet$ interference $\bullet$ population pharmacokinetics • streptavidin-biotin-based assay

Immunoassays that allow rapid measurement of analytes can be vital for the correct diagnosis of a broad range of diseases [1]. The interaction of streptavidin and biotin has been utilized for the development of robust and highly sensitive immunoassays by many manufacturers (Abbott, Beckman Coulter, Ortho Clinical Diagnostics, Roche Diagnostics, Siemens Healthcare Diagnostics and others). Biotin, a water-soluble vitamin, is a small and stable molecule that can be conjugated to many proteins without significantly affecting their biological activity; this interaction is the strongest known noncovalent binding between a protein and a ligand [2].

Exogenous biotin has the potential to interfere with streptavidin-biotin-based assay results. The impact of interference on test results can be the generation of falsely high values, obtained when using a competitive assay design, whereby an excess of biotin in the specimen competes with biotinylated analog for binding sites on streptavidin. Alternatively, when using a sandwich assay design, an excess of biotin in the specimen can displace biotinylated antibodies, which can generate falsely low values [3]. Reports of biotin interference leading to incorrect biochemical diagnoses in both adults and children have been published previously, along with warnings to clinicians and pathologists to interpret unexpected assay results with caution and consider the potential effect of biotin interference before making a diagnosis [4-7].

The normal serum concentration of biotin is very low; published average values range from below 0.1 to $0.8 \mathrm{ng} / \mathrm{ml}[8,9]$. The adequate daily intake of biotin is $30 \mu \mathrm{g} /$ day [10] and biotin deficiency is rare as the majority of diets contain enough biotin for this to be reached. However, biotin is increasingly being marketed as a lifestyle supplement which is claimed to strengthen hair and nails, despite no scientific confirmation of these benefits [11]. The unregulated, over-the-counter (OTC) product is available in doses ranging from $50 \mu \mathrm{g}$ found in multivitamin

Future Medicine 
tablets, to as high as $10 \mathrm{mg}$ in biotin-only products $[12,13]$. Consequently, the risk of biotin interference is increased for samples taken from patients choosing to take these supplements.

Guidance on how to mitigate the risk of biotin interference in streptavidin-biotin-based assays varies between manufacturers. The spectrum of guidance provided in package inserts ranges from no mention or a vague generic warning of biotin interference, which is insufficient as it does not create awareness of potential issues, to the more comprehensive specification of a serum biotin concentration below which assay interference is minimal, for example, $\leq 10 \%$ change; these thresholds vary from 10 to $500 \mathrm{ng} / \mathrm{ml}$, with the majority of thresholds being $>50 \mathrm{ng} / \mathrm{ml}$. To our knowledge, the Elecsys assays (Roche Diagnostics) are the only assays to specify a recommended washout period that would ensure that biotin concentrations are below the interference threshold following the last biotin administration [14-19].

Due to increasing doses of OTC biotin products and the broader acceptance of biotin as a dietary supplement, there is a need for greater understanding of biotin pharmacokinetic (PK) properties and clearer guidance for clinicians and pathologists on the use of streptavidin-biotin-based assays in this setting. The overall aim of this study was therefore to characterize the PK properties of biotin following high-dose regimens and evaluate the time needed for biotin concentrations to fall below a range of interference thresholds.

\section{Materials \& methods}

\section{Trial design}

This was an open-label, multiple-dose, single-center study. A total of 54 participants (male and female) provided a sufficient sample size for the collection of data for the derivation of PK model parameters.

\section{Objectives}

The objectives of the study were to characterize the PK properties of biotin using a population modeling approach, and to simulate biotin concentrations following different dosing regimens. Additionally, biotin PK properties were used to assess the time necessary for biotin concentrations to fall below a range of interference thresholds following last intake.

\section{Participants}

Apparently healthy participants (no known chronic or acute disease) aged $\geq 18$ years were enrolled in the study. Participants were not eligible for enrollment if they were taking anticonvulsants, biotin or multivitamins, if they had a known intolerance to biotin or lactose or if they were participating in other trials during the active study phase. Pregnant women and breast-feeding mothers were also excluded from the study.

\section{Standard protocol approvals, registration \& patient consents}

The clinical study protocol was approved by Ethik-Kommission der Bayerischen Landesärztekammer. The study was performed in accordance with ethical principles consistent with the Declaration of Helsinki and the International Council for Harmonisation of Technical Requirements for Pharmaceuticals for Human Use/Good Clinical Practice. Written informed consent was obtained from all participants before study initiation.

\section{Interventions}

Participants were divided into three different dosing groups (5, 10 or $20 \mathrm{mg}$ ). Each group was comprised of equal proportions of male and female participants. Participants were required to fast for $8 \mathrm{~h}$ prior to, and $1 \mathrm{~h}$ after, biotin intake. Biotin ( 5 mg tablet: $\times 1, \times 2$ or $\times 4$ depending on group) was administered orally, once daily, at the same time on 5 consecutive days. Blood samples were collected prior to biotin intake on Days 1, 2 and 7, and at 1, 3, 6, 8 and $12 \mathrm{~h}$ postdose on Days 3 and 7.

\section{Biotin measurements}

Samples were measured on the cobas e 411 analyzer (Roche Diagnostics GmbH, Mannheim, Germany) using an in-house competitive Elecsys research assay, which detects total serum biotin (free biotin, bound biotin/biocytin and biotin metabolites). Samples were incubated with a streptavidin-ruthenium conjugate followed by the addition of a poly-biotinylated antibody that binds to still vacant biotin-binding sites on the streptavidin-ruthenium conjugate and to the streptavidin-coated microparticles. The reaction mixture was then aspirated into the measuring cell where the microparticles were magnetically captured onto the surface of the electrode. Unbound substances were 
removed with ProCell/ProCell M. Application of a voltage to the electrode induced chemiluminescent emission that was measured by a photomultiplier. Results were determined via a calibration curve which was generated prior to serum sample measurements using D-biotin standards. Those samples with a biotin concentration above the measuring range $(0.1-0.75 \mathrm{ng} / \mathrm{ml})$ were diluted, and results were subsequently multiplied by the dilution factor.

Assay quality was monitored using internal run controls and human serum samples spiked with a defined amount of D-biotin.

\section{Pharmacokinetic model}

The population PK model was developed using the first-order conditional estimation interaction method in NONMEM $^{\circledR}$ version 7.3 (Icon Development Solutions, MD, USA). Simulations were also performed with NONMEM. The analysis and simulation datasets, as well as graphics, were created using $S A S^{\circledR}$ System for Windows ${ }^{\circledR}$ version 9.4 TS Level $1 \mathrm{M} 2$. Validation checks were conducted by creating diagnostic plots using all PK data variables in order to identify possible errors or outliers.

A preliminary population PK model was developed using existing data (not shown) and used as a basis for this analysis. The model was a two-compartment disposition model, with first-order absorption and elimination. The best residual error model was a multiplicative error model. The PK model parameters were apparent clearance $(\mathrm{CL} / \mathrm{F})$, apparent volume of distribution of the central compartment $(\mathrm{V} 2 / \mathrm{F})$, apparent intercompartmental clearance $(\mathrm{Q} / \mathrm{F})$, apparent volume of distribution of the peripheral compartment (V3/F), first-order absorption rate constant (KA) and lag time (TLAG). Graphical analyses were conducted to investigate any impact of the following baseline characteristics (i.e., covariates) on the PK of biotin: age, gender, race, weight, height, BMI and dose.

\section{Final model selection criteria}

Final model development and selection were based on various goodness-of-fit indicators. The final model was identified by using the following criteria: minimization obtained successfully in NONMEM; covariance step obtained successfully; at least three significant figures obtained for all $\theta$ estimates and final estimates of population PK parameters were not close to the initial estimate boundaries. It was required that there should be no trends in the following goodness-of-fit plots: population and individual predictions versus observations; conditional weighted residuals versus population predictions versus time; individual weighted residuals versus individual predictions versus time; individual plots comparing observed and individual predictions over time.

\section{Effective half-life \& accumulation ratio}

The population PK parameters from the final biotin model were used to compute the biotin-effective half-life. An effective half-life $\left(\mathrm{t}_{1 / 2, \text { eff }}\right)$ was computed for the two-compartment PK model, taking into account the contribution of each phase of the PK profile to the elimination process. The accumulation ratio, based on the AUC, was also computed, taking into account the contribution of each phase of the PK profile.

\section{Model predictive performance}

The predictive performance of the population PK model was evaluated by conducting a visual predictive check (VPC). This approach aimed to verify the agreement between observed data from the biotin interference study and the simulated data using the parameters from the final population PK model. Since the simulations of different dosing regimens were conducted with the individual post-hoc PK parameters $(\mathrm{n}=54)$, those parameters were used for the VPC and were randomly sampled and assigned to each dose group. For each individual, dosing information and sampling times were identical to those contained in the original dataset (used for model development). This process was then repeated 100 times for the entire dataset. For each simulation, median, 5th and 95th percentiles were calculated; the $90 \%$ confidence interval (using the 5th and 95th percentiles) was computed from results of the 100 simulation runs. Median, 5th and 95th percentiles derived from observed data were then superimposed on the same graph and compared with predicted $90 \%$ confidence intervals.

\section{Simulations of biotin concentrations for different dosing regimens}

Individual PK parameters (i.e., KA, CL/F, V2/F, Q/F and V3/F) of the 54 participants (who received biotin 5, 10 or $20 \mathrm{mg}$ once daily) included in the NONMEM analysis were used to perform the simulations with several very high biotin doses $(1,2.5,5,10,20,100$ and $300 \mathrm{mg})$ and several dosing frequencies: single dose (s.d.); multiple 


\begin{tabular}{|c|c|c|c|c|}
\hline & 5 -mg biotin $(n=18)$ & $10-\mathrm{mg}$ biotin $(\mathrm{n}=18)$ & 20 -mg biotin $(n=18)$ & Total $(n=54)$ \\
\hline Mean age, years (range) & $43.9(19-66)$ & $48.2(21-72)$ & $35.9(19-58)$ & $42.7(19-72)$ \\
\hline \multicolumn{5}{|l|}{ Sex, $n(\%)$} \\
\hline - Female & $9(50)$ & $9(50)$ & $9(50)$ & $27(50)$ \\
\hline - Male & $9(50)$ & $9(50)$ & $9(50)$ & $27(50)$ \\
\hline \multicolumn{5}{|l|}{ Race, $n$ (\%) } \\
\hline - White & $17(94)$ & $18(100)$ & $18(100)$ & $53(98)$ \\
\hline Mean BMI, kg/m² (SD) & $25.1(4.8)$ & $24.9(2.5)$ & $24.4(4.0)$ & 24.8 (3.8) \\
\hline
\end{tabular}

BMI: Body mass index; SD: Standard deviation.

doses up to steady state: once a day (q.d.); twice a day (b.i.d.): 8:00 am and 8:00 pm; three-times a day (t.i.d.): 8:00 am, 12:00 pm and 8:00 pm; four-times a day (q.i.d.): 8:00 am, 12:00 pm, 4:00 pm and 8:00 pm.

For each dosing regimen, biotin concentration-time profiles were simulated every $0.5 \mathrm{~h}$ from the time of last drug intake up to $24 \mathrm{~h}$ after the last drug intake and then every hour up to $250 \mathrm{~h}$ after the last drug intake.

Simulated biotin concentration-time profiles were summarized by dosing regimen using descriptive statistics. The times needed for biotin concentration percentiles to fall below different thresholds ranging from 10 to $100 \mathrm{ng} / \mathrm{ml}$ were computed.

\section{Results}

\section{Patient characteristics}

Between 22 September 2016 and 12 October 2016, 54 participants were enrolled in the study. Participant demographics are summarized in Table 1; the proportion of males and females, and mean BMI was consistent across the doses studied and $98 \%$ of the participants were White. The mean age of participants in the 20-mg group was slightly lower than that in the other two groups (Table 1). All 54 received treatment and completed the study. In total, 702 samples were collected for analysis. No serious adverse events were recorded during the study period. In total, nine adverse events occurred; all were deemed unlikely to be related to the study.

\section{Biotin measurements \& PK}

The performance of the assay was assessed to ensure the accuracy of the results. The overall assay performance was good. Recoveries of internal run controls ranged from 94 to $106 \%$ and interassay CVs were $\leq 4 \%$. No drift in signal within runs was detected (end measurement taken at $\sim 6-8 \mathrm{~h}$ ). Recoveries of human serum control samples ranged from 87 to $113 \%$ and interassay CVs were $\leq 6 \%$.

PK analysis showed that the biotin concentration was dose proportional within the studied range; Figure 1 shows the median biotin concentrations for all groups. The median (minimum-maximum) peak biotin concentration on Day 3 (1-h postdose) was $41(10-73) \mathrm{ng} / \mathrm{ml}, 91(53-141) \mathrm{ng} / \mathrm{ml}$ and $184(80-355) \mathrm{ng} / \mathrm{ml}$ for the 5, 10 and $20 \mathrm{mg}$ groups, respectively. Following 5 days of consecutive dosing (q.d.), accumulation was observed for each group, with the majority of values doubled $6 \mathrm{~h}$ postdose on Day 7 compared with the same time point on Day 3. PK analysis showed linear PK over the range of doses (5-20 mg) and time (first dose to steady state). Absorption was rapid, with a maximum serum concentration $\left(\mathrm{t}_{\max }\right)$ of less than $1 \mathrm{~h}$.

\section{Pharmacokinetic model} Final model selection

The PK of biotin was found to be appropriately described by the two-compartment disposition model, with first-order absorption and elimination. NONMEM population parameters are shown in Table 2. The population PK parameters were well estimated with a standard error of less than $10 \%$. Interindividual variability ranged from 13.8 to $21.7 \%$.

The covariates investigated (weight, height and age) had minimal impact on CL, V2/F and F1, and thus were not further investigated in the population PK analysis. No trends were observed in the population or individual predictions versus observations, or in weighted residual plots. No effect of dose on the PK parameters was observed. 


\section{Biotin concentration in serum}

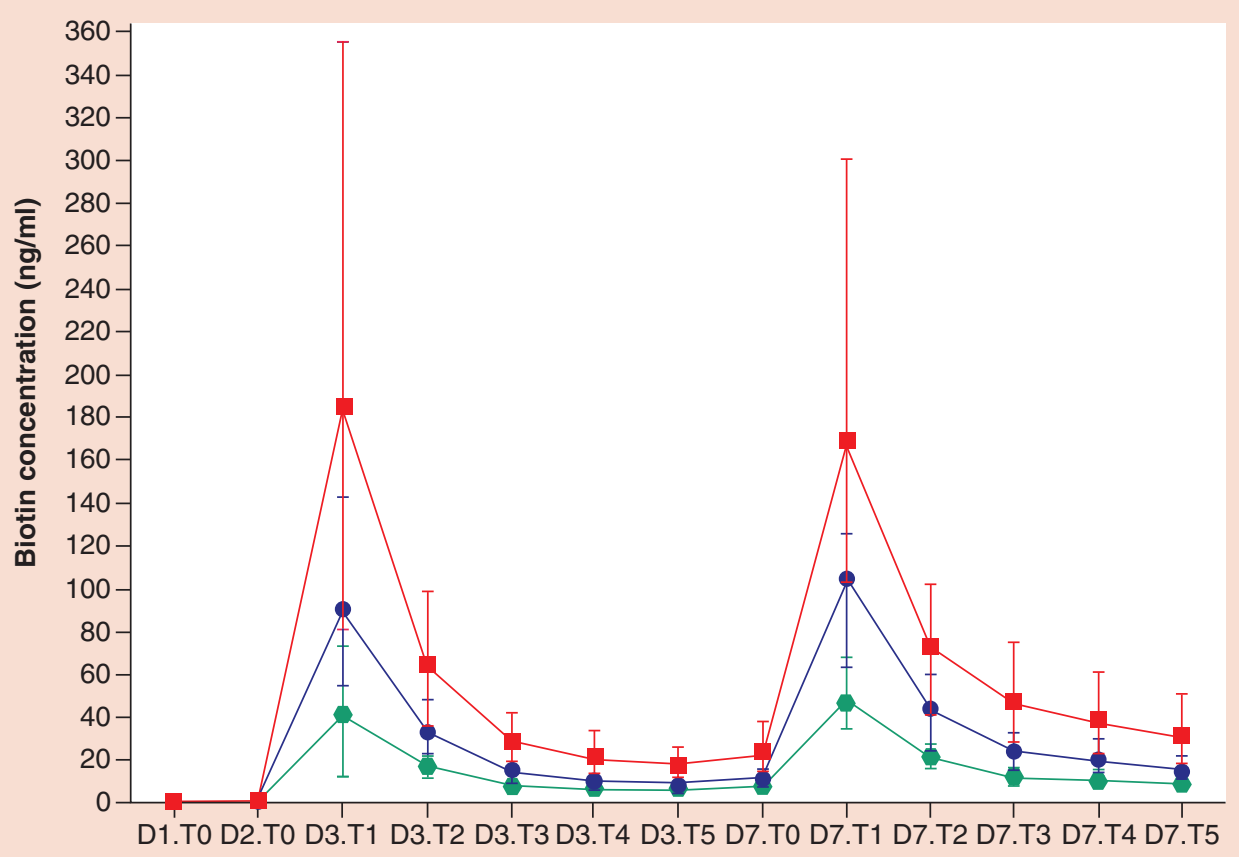

Dosage group 1

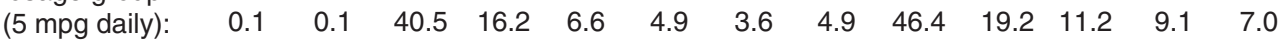

Dosage group 2

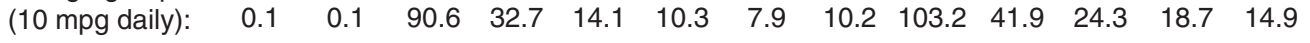

Dosage group 3

(20 mpg daily):

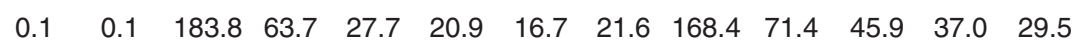

Figure 1. Median (minimum-maximum) biotin concentration in serum ( $\mathrm{ng} / \mathrm{ml})$ for each dosing group $(5,10$ and $20 \mathrm{mg})$.

D: Day; T0: Prebiotin intake; T1: 1-h postdose; T2: 3-h postdose; T3: 6-h postdose; T4: 8-h postdose; T5: 12-h postdose.

\section{Table 2. NONMEM population parameter values for the final run with the biotin pharmacokinetic model.}

\begin{tabular}{|c|c|c|}
\hline Parameter & Estimate & Standard error (\%) \\
\hline $\mathrm{CL} / \mathrm{F}$ & $17.4 \mathrm{I} / \mathrm{h}$ & 2.50 \\
\hline $\mathrm{V} 2 / \mathrm{F}$ & 73.21 & 3.50 \\
\hline V3/F & 3011 & 5.70 \\
\hline $\mathrm{Q} / \mathrm{F}$ & $24.1 \mathrm{I} / \mathrm{h}$ & 3.50 \\
\hline $\mathrm{KA}$ & $7.12 \mathrm{~h}$ & 9.60 \\
\hline Lag time & $0 \mathrm{~h}$ (fixed) & NA \\
\hline F1 & 1 (fixed) & NA \\
\hline $\mathrm{CL}$ & $13.8 \%$ & 47.8 \\
\hline VC & $20.2 \%$ & 32.4 \\
\hline F1 & $21.7 \%$ & 24.3 \\
\hline$\sigma$ (proportional) & 14.4 & 6.8 \\
\hline
\end{tabular}




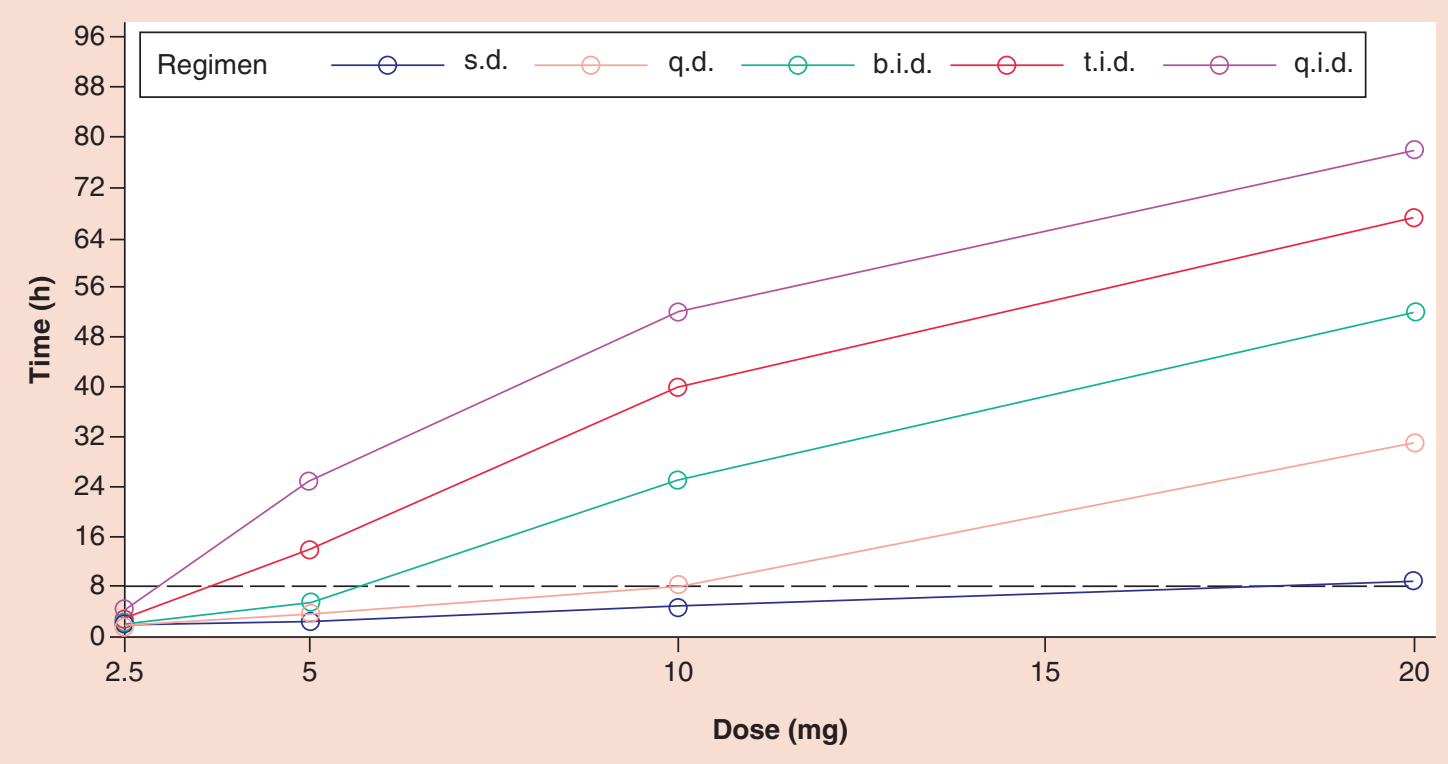

Figure 2. Simulation of time required for biotin serum concentration to fall below $30 \mathrm{ng} / \mathrm{ml}$ following biotin intake in the $\mathbf{5 4}$ participants characterized in the pharmacokinetic study.

b.i.d.: Twice a day; q.d.: Once daily; q.i.d.: Four-times a day; s.d.: Single dose; t.i.d.: Three-times a day.

\section{Effective halflife \& accumulation ratio}

The effective half-life was calculated to be $15 \mathrm{~h}$, indicating that steady state would be reached in approximately 3 days. The AUC accumulation ratios were 1.4 and 1.8 for once daily and twice a day dosing, respectively.

\section{Model predictive performance}

A VPC of the predictive performance of the PK model was conducted for all dose groups at Day 3 and Day 7 to ensure accuracy of the model. The median, fifth and 95th percentiles of the observed PK profiles were contained in their respective CIs indicating that the set of 54 individual PK parameters captures both the central tendency and the interindividual variability of biotin pharmacokinetics.

\section{Simulations of biotin concentrations for different dosing regimens}

It is important to understand the time taken for the serum biotin concentration to fall below a specific threshold, to allow calculation of the washout period required before collection of serum samples for assessment using biotinstreptavidin based assays. Figure 2 shows the time needed for the biotin concentration to fall below $30 \mathrm{ng} / \mathrm{ml}$ following various dosing regimens in the 54 participants characterized in the PK study. The threshold of $30 \mathrm{ng} / \mathrm{ml}$ was chosen as a conservative approach to calculate the washout times, as for many assays, the biotin threshold is $>50 \mathrm{ng} / \mathrm{ml}$. Following doses of biotin at 5, 10 or $20 \mathrm{mg}$ q.d. for 5 days, the $30 \mathrm{ng} / \mathrm{ml}$ interference threshold was reached within $3.5,8$ or $31 \mathrm{~h}$, respectively. Supplementary Table 1 summarizes the time required for the biotin concentration to fall below thresholds ranging from 10 to $100 \mathrm{ng} / \mathrm{ml}$, for each of the dose regimens simulated.

\section{Discussion}

This study aimed to characterize the PK properties of biotin and establish a PK model to simulate different highdose regimens. These data are important as the use of OTC biotin supplements is increasing, and the strength of available doses is rising. Therefore clinicians and pathologists need to be confident that any recommendations for biotin interference thresholds or washout periods are sufficient to mitigate the risk for potential assay interference. To this end, validation or strengthening of data surrounding thresholds or washout periods stated on package inserts can help reassure clinicians and pathologists that accurate diagnoses can be made using these assays.

Results of the population PK analysis showed that biotin has linear PK over the range of doses studied (5-20 mg), is rapidly absorbed and has an effective serum half-life of $15 \mathrm{~h}$. Following consecutive dosing over several days, 
accumulation of biotin was observed within each dosing group; however, data analysis revealed that steady state is reached after 3 days of biotin intake.

The PK model showed very good predictive performance, indicating that simulations from the model can provide additional guidance on the use of washout times depending on assay-specific biotin interference thresholds. However, interindividual variability for clearance was moderate (13.8-21.7\%) and the model was based on data from healthy participants. By including apparently healthy participants, the study more accurately reflects real-life situations, where renal function may be unknown and a spectrum of renal function is expected. The results should be interpreted with care; particularly in patients with impaired renal function where the half-life of biotin may be longer $[4,8]$.

The results of the population PK analysis demonstrate that for biotin dosing regimens up to daily doses of $1 \mathrm{mg}$, as found in OTC supplements/multivitamin pills (i.e., more than 80-fold the adequate daily intake for biotin), serum biotin levels fell below an in vitro threshold of $10 \mathrm{ng} / \mathrm{ml}$ (one of the lowest recommended biotin interference thresholds [18]) after $2 \mathrm{~h}$ (Supplementary Table 1). For doses of biotin of up to $10 \mathrm{mg} /$ day (e.g., $5 \mathrm{mg}$ twice daily or $10 \mathrm{mg}$ once daily; more than 300-fold the adequate daily intake of biotin), an in vitro serum biotin threshold of $30 \mathrm{ng} / \mathrm{ml}$ was consistently reached after $8 \mathrm{~h}$.

Following extremely high doses of biotin ( $\geq 20 \mathrm{mg}$ q.d.; more than 500 -fold the adequate daily intake), the residual biotin serum concentration did not drop to $30 \mathrm{ng} / \mathrm{ml}$ until $31 \mathrm{~h}$ after last intake, and took $73 \mathrm{~h}$ to drop to $10 \mathrm{ng} / \mathrm{ml}$. Therefore, in rare cases where extremely high doses of biotin are administered, extended washout periods would be needed for some immunoassays, particularly those with a low in vitro interference threshold $(<30 \mathrm{ng} / \mathrm{ml})$.

A limitation of this study was that it was designed to relate in vivo biotin serum levels to in vitro interference thresholds. Consequently, the data do not directly provide information on the clinical relevance of biotin interference. Specifically, the present study does not give information on the size of any potential effect of biotin interference on test results or the proportion of laboratory values that are near a medical decision point and thus potentially vulnerable to interference. Future investigations could aim to address this limitation but in vitro thresholds will continue to be the accepted approach until robust methods of assessing biotin interference in vivo are published. Also, it could be argued that results of biotin measurements would be better presented in nmol $/ \mathrm{l}$ rather than $\mathrm{ng} / \mathrm{ml}$ since the MWs of the main metabolites of biotin are different. However, both of these units create uncertainty in relation to biotin metabolites, and the specific metabolites present and their concentrations are unknown.

This study used the cobas e 411 analyzer and an in-house research kit to detect total biotin in the serum samples. This was chosen over other methods, such as LC-MS as the research kit measures total serum biotin, including free biotin, bound biotin/biocytin and biotin metabolites, all of which can interfere with streptavidin-biotin-based assays.

In a recent study investigating the extent of biotin interference with Roche Elecsys thyroid assays (free thyroxine, thyroid-stimulating hormone, total triiodothyronine and total thyroxine) using the Roche cobas e 601 immunoassay platform, the experimentally derived biotin interference thresholds corroborated the corresponding Roche package (free thyroxine: $61 \mathrm{ng} / \mathrm{ml}$ [package insert threshold: $25 \mathrm{ng} / \mathrm{ml}$ ]; total thyroxine: $348 \mathrm{ng} / \mathrm{ml}$ [100 ng/ml]; total triiodothyronine: $19 \mathrm{ng} / \mathrm{ml}$ [10 ng/ml]; thyroid-stimulating hormone: $30 \mathrm{ng} / \mathrm{ml}$ [20 ng/ml]). Additionally, it was found that treating 0.45 - $\mathrm{ml}$ biotin-spiked serum with 0.05 - $\mathrm{ml}$ streptavidin agarose beads for $1 \mathrm{~h}$ effectively removed biotin and eliminated interference [20], highlighting that if biotin interference is suspected, additional steps can be taken by the laboratory in order to reduce the risk of a false result.

The biotin doses administered in this study were chosen to reflect the high doses of biotin that are available to take as a lifestyle supplement $(50 \mu \mathrm{g}-10 \mathrm{mg})$, which can be purchased OTC, despite no available clinical evidence to support the claims that it leads to the desired improvements in health of hair and nails [11]. It should be noted that the doses examined were approximately 100- to 500-times higher than the recommended daily intake of $30 \mu \mathrm{g} /$ day [10]. Higher doses were also simulated; currently, very-high biotin doses are only being used in the clinical trial setting, as a potential treatment for multiple sclerosis $[21,22]$. A study in healthy volunteers $(\mathrm{n}=8)$ found that, following a single 100 or $300 \mathrm{mg}$ dose of biotin, median $t_{\max }$ occurred at 1.25 and $1.5 \mathrm{~h}$, respectively. Elimination half-lives varied from 7.8 to $18.8 \mathrm{~h}$, which are consistent with the elimination half-life observed in our study (15 h) [23]. The slight food effect observed by Peyro Saint Paul et al. [23] was avoided in our study by administration of biotin in the fasted state only. Also, biotin accumulation was observed in our study, which is in contrast to animal studies detailed by Peyro Saint Paul et al. [23] where no accumulation was reported. 
The degree of biotin interference varies widely between assays and manufacturers of immunoassays are expected to disclose the identity of any substance that may interfere with their assay results. At the time of writing, few assays include statements on the serum biotin concentration thresholds required to avoid assay interference, or guidance on the necessary washout periods in their package inserts. Although our study used a washout period of $8 \mathrm{~h}$ as stated in the package insert of the specific Elecsys assay used, it is important to note that this should not be extrapolated to other assays where a washout period is not given in the package insert. However, the PK characteristics of biotin are independent of assay design; therefore, biotin half-life and plasma levels can still be used to relate to assay-specific thresholds and thus, to estimate corresponding washout periods for any assay. As some thresholds will be calculated using the total biotin concentration (i.e., including metabolites), and others will not measure biotin metabolites, cross-assay comparisons are difficult. Following a number of recent publications discussing case reports of biotin interference causing erroneous results [5-7], it is advised that clinicians review the supplements taken by their patients in addition to their prescribed medication. Laboratories and pathologists should also be aware of which assays are vulnerable to biotin interference, and communicate the specified washout periods to clinicians, when provided in the package insert of the specific assays used. Additionally, it is important for clinicians and pathologists to be aware of which immunoassays are streptavidin-biotin-based and therefore when an abnormal result may be the result of interference and require repeat analysis before a diagnosis is made [4].

\section{Conclusion}

In summary, our findings provide clear guidance on washout periods required for assays with interference thresholds ranging from 10 to $100 \mathrm{ng} / \mathrm{ml}$, following biotin intake at dose regimens of $1 \mathrm{mg}$ s.d. to $300 \mathrm{mg}$ q.i.d. For assays with an in vitro interference threshold of $\geq 30 \mathrm{ng} / \mathrm{ml}$, our simulations show that for patients taking biotin doses of up to $5 \mathrm{mg}$ b.i.d. or $10 \mathrm{mg}$ q.d., an 8 -h washout period is sufficient to mitigate the risk of biotin interference. For a minority of assays with an in vitro interference threshold of $<30 \mathrm{ng} / \mathrm{ml}$, or in the rare case of patients taking biotin at $\geq 10 \mathrm{mg}$ daily doses, it is necessary to delay sample collection for a longer period (up to $73 \mathrm{~h}$ ) after the last dose of biotin in order to avoid the risk of false assay results.

\section{Future perspective}

Healthcare is becoming increasingly personalized, as underlying mechanisms of disease continue to be elucidated and different patient subpopulations are described. Accordingly, companion diagnostics, including immunoassays, will continue to play a vital (and increasing) role in medicine. Streptavidin-biotin assays are commonplace, and their use is likely to continue. In parallel, the use of biotin supplements as lifestyle products of hair and nails, regardless of evidence, may continue to increase. Thus, for the foreseeable future, clear recommendations on the use of streptavidin-biotin assays in light of biotin supplement use will remain critical. The results presented here give clear guidance on washout periods needed for a range of biotin doses before the use of streptavidin-biotin immunoassays. These results will allow clinicians and pathologists to have confidence that the recommended washout periods are sufficient, even with patients who have taken high doses of biotin.

\section{Acknowledgements}

Thanks to all the individuals who participated in this study, which was conducted with Nuvisan GmbH, Neu-Ulm, Germany. The authors would like to acknowledge A Goncalves and A Schuetzenmeister for their contributions to the study, C Chowanetz and S Gaupp from TRIGA-S Scientific Support e.K. for their contributions as CRAs.

Financial \& competing interests disclosure

The study was funded by Roche Diagnostics. P Grimsey, N Frey, G Bendig, J Zitzler, O Lorenz, D Kasapic \& CE Zaugg are employees of Roche, and P Grimsey and CE Zaugg hold stock options. The authors have no other relevant affiliations or financial involvement with any organization or entity with a financial interest in or financial conflict with the subject matter or materials discussed in the manuscript apart from those disclosed.

Writing assistance was utilized in the production of this manuscript. The authors would like to thank L Evans, MNeuroSci of Gardiner-Caldwell Communications, Macclesfield, UK, an Ashfield Company, part of UDG Healthcare plc for medical writing support that was funded by Roche Diagnostics in accordance with Good Publications Practice (GPP3) guidelines (www.ismpp.org/ gpp3). 


\section{Ethical conduct of research}

The authors state that they have obtained appropriate institutional review board approval or have followed the principles outlined in the Declaration of Helsinki for all human or animal experimental investigations. In addition, for investigations involving human subjects, informed consent has been obtained from the participants involved.

\section{Open access}

This work is licensed under the Attribution-NonCommercial-NoDerivatives 4.0 Unported License. To view a copy of this license, visit http://creativecommons.org/licenses/by-nc-nd/4.0/

\section{Supplementary data}

To view the supplementary data that accompany this paper please visit the journal website at: www.futurescience.com/doi/full/10.4155/ipk-2017-0013

\section{Summary points}

- Biotin in human serum is a potential interfering factor for all streptavidin-biotin-based assay designs.

- Use of high doses of biotin as an over-the-counter lifestyle supplement is increasing, therefore the potential risk of erroneous immunoassay results due to biotin interference is growing.

- Biotin had linear pharmacokinetic over the range of doses studied (5-20 mg), was rapidly absorbed and had an effective serum half-life of $15 \mathrm{~h}$ (steady-state reached in 3 days).

- The time taken for biotin doses to drop below thresholds of $10-100 \mathrm{ng} / \mathrm{ml}$ was simulated for dosing regimens ranging from $1 \mathrm{mg}$ s.d. to $300 \mathrm{mg}$ q.i.d.

- For biotin regimens of $\leq 10 \mathrm{mg}$ q.d. (10 $\mathrm{mg}$ is $>300$-times the adequate daily intake), serum biotin levels were below an in vitro interference threshold of $\geq 30 \mathrm{ng} / \mathrm{ml}$ after $8 \mathrm{~h}$.

- If the in vitro interference threshold of an immunoassay is $<30 \mathrm{ng} / \mathrm{ml}$, or in the extreme cases of patients taking a daily dose of $>10 \mathrm{mg}$, extended washout periods are recommended.

\section{References}

Papers of special note have been highlighted as: • of interest; $\bullet \bullet$ of considerable interest

1 Rulander NJ, Cardamone D, Senior M, Snyder PJ, Master SR. Interference from anti-streptavidin antibody. Arch. Pathol. Lab. Med. 137, 1141-1146 (2013).

2 Diamandis EP, Christopoulos TK. The biotin-(strept)avidin system: principles and applications in biotechnology. Clin. Chem. 37, 625-636 (1991).

- Gives a general overview of the biotin-streptavidin system, describing its components and advantages, and showing how the system is used in various applications.

3 Piketty ML, Polak M, Flechtner I, Gonzales-Briceno L, Souberbielle JC. False biochemical diagnosis of hyperthyroidism in streptavidin-biotin-based immunoassays: the problem of biotin intake and related interferences. Clin. Chem. Lab. Med. 55, 780-788 (2017).

4 Samarasinghe S, Meah F, Singh V et al. Biotin interference with routine clinical immunoassays: understand the causes and mitigate the risks. Endocr. Pract. 23(8), 989-998 (2017).

-. Reviews the mechanisms of biotin interference with biotin-streptavidin-based immunoassays and describes how to estimate and minimize the risk of biotin interference in vulnerable assays. Provides a review of the literature pertaining to biotin interference in endocrine function tests.

5 Kwok JS, Chan IH, Chan MH. Biotin interference on TSH and free thyroid hormone measurement. Pathology 44, 278-280 (2012).

- Describes a case in a 3-year-old patient with unusual thyroid function test results due to biotin interference.

6 Wijeratne NG, Doery JC, Lu ZX. Positive and negative interference in immunoassays following biotin ingestion: a pharmacokinetic study. Pathology 44, 674-675 (2012).

- Describes a case in a 1-week-old patient with unusual thyroid function test results due to biotin interference.

7 Sulaiman RA. Biotin treatment causing erroneous immunoassay results: a word of caution for clinicians. Drug Discov. Ther. 10, 338-339 (2016).

- Describes three cases of erroneous thyroid function test results in adults due to biotin interference.

8 Livaniou E, Evangelatos GP, Ithakissios DS, Yatzidis H, Koutsicos DC. Serum biotin levels in patients undergoing chronic hemodialysis. Nephron 46, 331-332 (1987).

9 Clevidence BA, Marshall MW, Canary JJ. Biotin levels in plasma and urine of healthy adults consuming physiological doses of biotin. Nutr. Res. 8, 1109-1118 (1988). 
10 Institute of Medicine (US) Standing Committee on the Scientific Evaluation of Dietary Reference Intakes and its Panel on Folate, Other B Vitamins, and Choline. Dietary Reference Intakes for Thiamin, Riboflavin, Niacin, Vitamin B6, Folate, Vitamin B12, Pantothenic Acid, Biotin, and Choline. The National Academies Press (US), Washington, DC, USA (1998). https://doi.org/10.17226/6015

11 Trueb RM. Serum biotin levels in women complaining of hair loss. Int. J. Trichology 8, 73-74 (2016).

12 Abtei. Abtei Haut + Haare + Nägel. www.abtei.de/produkte/haut-haare-naegel/haut-haare-naegel/abtei-haut-haare-naegel/

13 Abtei. Abtei Biotin 10 mg. www.abtei.de/produkte/haut-haare-naegel/biotin/abtei-biotin-10mg/

14 Abbott ARCHITECT 20-OH Vitamin D assay. www.accessdata.fda.gov/cdrh_docs/reviews/K110619.pdf

15 Beckman Coulter Access Free T4 assay. www.beckmancoulter.com/wsrportal/ajax/downloadDocument/B01902B.pdf?autonomyId= TP_DOC_95467\&documentName=B01902B.pdf

16 Ortho-clinical diagnostics. VITROS Immunodiagnostic Products TSH Reagent Pack. www.cmmc.org/cmmclab/IFU/TSH_GEM1001_WW_EN_I.pdf

17 Siemens Healthcare Diagnostics. ADVIA Centaur HIV Ag/Ab Combo (CHIV) Assay. www.fda.gov/downloads/BiologicsBloodVaccines/BloodBloodProducts/ApprovedProducts/PremarketApprovalsPMAs/UCM450406.pdf

18 Siemens Healthcare Diagnostics. ADVIA Centaur TniUltra Assay. www.accessdata.fda.gov/scripts/cdrh/cfdocs/cfres/res.cfm?id=146020

19 Roche Elecsys Anti-HCV assay. www.accessdata.fda.gov/cdrh_docs/pdf9/P090009c.pdf

20 Katzman BM, Rosemark C, Hendrix BK, Block DR, Baumann NA. Investigation of biotin interference in common thyroid function tests using the Roche Elecsys immunoassay system. Clin. Chem. 62(Suppl. 10), A-260 (2016).

-. Reports results of a study investigating the extent of biotin interference with Roche Elecsys thyroid assays showing that the experimentally derived biotin interference thresholds corroborated the corresponding Roche package insert thresholds.

21 Tourbah A, Lebrun-Frenay C, Edan G et al. MD1003 (high-dose biotin) for the treatment of progressive multiple sclerosis: a randomised, double-blind, placebo-controlled study. Mult. Scler. 22, 1719-1731 (2016).

22 Sedel F, Papeix C, Bellanger A et al. High doses of biotin in chronic progressive multiple sclerosis: a pilot study. Mult. Scler. Relat. Disord. 4, 159-169 (2015).

23 Peyro Saint Paul L, Debruyne D, Bernard D, Mock DM, Defer GL. Pharmacokinetics and pharmacodynamics of MD1003 (high-dose biotin) in the treatment of progressive multiple sclerosis. Expert Opin. Drug Metab. Toxicol. 12, 327-344 (2016).

- Reports results of a small randomized, crossover pharmacokinetic study evaluating biotin in healthy volunteers $(n=8)$. 